\title{
Cartografias Subalternas: travessias epistemológicas para a Ciência da Informação
}

\author{
Subaltern Cartographies: epistemological paths for Information Science
}

\begin{abstract}
Jéssica Paola Macedo Müller a (1)
Rodrigo Silva Caxias de Sousa b,*

RESUMO: Neste trabalho propomos uma interpretação do percurso de conformação dos estudos pós-coloniais e decoloniais. Para executá-la, através de pesquisa bibliográfica, caracterizamos o pós-colonialismo e a decolonialidade, que surgem como tensionamentos epistemológicos resultantes do processo de luta e de resistência contra a colonização. Assimilamos o contexto de surgimento, o florescimento, os campos de disputa, as proposições de ruptura, as continuidades, os contrastes e as reivindicações das duas perspectivas. A discussão teórica é baseada no pensamento crítico latino-americano que elabora a sua crítica à hegemonia através das Teorias Sociais do Sul. Com vistas à explicitação das devidas distinções temáticas, efetuamos o levantamento bibliográfico a partir de diferentes fontes de informação. A pesquisa possui caráter exploratório-investigativo e abordagem qualitativa. As interpretações dos resultados seguem as pistas da concreticidade histórica por meio de percepções dos modos de desenvolvimento da cartografia epistemológica, utilizando-se da dialética para desvelar os territórios epistêmicos pós-coloniais e decoloniais. Por fim, compreendemos que a permanência das colonialidades na América Latina é fruto das disputas, das dependências, das contradições e das resistências que ultrapassam fronteiras e que não se encerram em binarismos como Norte e Sul. As colonialidades devem ser analisadas em sua complexidade e refinamento, uma vez que operam na formação de elites intelectuais e econômicas e na conformação do discurso científico, percebidas, inclusive, de modo residual nos estudos que se propõem alternativos.
\end{abstract}

Palavras-chave: Cartografia Epistemológica; Descolonização Epistemológica; Estudos Pós-coloniais; Estudos Decoloniais.

ABSTRACT: This research aims to analyze postcolonial and decolonial studies through bibliographical research. It investigates the development of postcolonialism and decoloniality that emerge as epistemological alternatives resulting from the process of struggle and resistance to colonization. It assimilates the circumstances of emergence and development, as well as the fields of discussion, disconnections, connections, contrasts, and interests of both theories. The theoretical discussion is based on Latin-American critical thought. To analyze the phenomenon, we conducted a survey from different sources of information. The research has an exploratoryinvestigation character and a qualitative approach. To understand the development of epistemological cartography, it uses dialectic to unveil the postcolonial and decolonial epistemic territories. Finally, it understands that the permanence of coloniality is the result of struggles, dependencies, contradictions, and resistances that cross borders and do not end in the North and South binomial. To analyze this issue, one must consider the complexity and refinement of the colonialities that form the intellectual and economic elites and structure scientific discourse, including studies that emerge as epistemological alternatives.

Keywords: Epistemological Cartography; Decolonization of Knowledge; Postcolonial Studies; Decolonial Studies.

a Universidade Federal do Rio Grande do Sul, Porto Alegre, RS, Brasil.

b Departamento de Ciências da Informação, Universidade Federal do Rio Grande do Sul, Porto Alegre, RS, Brasil.

*Correspondência para/Correspondence to: Rodrigo Silva Caxias de Sousa. E-mail: rodrigo.caxias@ufrgs.br.

Recebido em/Received: 25/06/2021; Aprovado em/Approved: 03/11/2021.

Artigo publicado em acesso aberto sob licença CC BY 4.0 Internacional ()( 


\section{INTRODUÇÃO}

As profundas diferenças cognitivas entre os países imperialistas e os países subalternos, as quais são originadas a partir da instituição de um sistema de dominação colonial e de sua rearticulação na contemporaneidade, são delineadas por linhas abissais, conceito elaborado por Santos (2007) para ilustrar a formação da cartografia epistemológica. Esta se refere aos territórios imbricados nos processos de colonialismo e de neocolonialismo que possuem desigualdades sociais, políticas, econômicas e culturais intensamente marcadas.

Os estudos pós-coloniais e decoloniais emergem, nesse contexto, como formas de tensionamento da epistemologia dominante na medida em que tematizam questões fundamentais para o enfrentamento da abissalidade (profundas diferenças simbólicas e concretas que têm origem histórica), buscando alternativas não-hegemônicas na análise social, na proposição de soluções para problemas estruturais e, consequentemente, na produção de conhecimento.

Entretanto, tais estudos, ainda que se proponham alternativos, mostram-se concentrados nos territórios acadêmicos que possuem relação com os países que predominam na produção científica, sendo atravessados pelos interesses de tais agentes. Neste sentido, o uso da dialética para explicitar as convergências e as distinções entre esses estudos nos permite observar os matizes, as nuances e os contrastes que se materializam no campo da disputa intelectual.

Outrossim, mostra-se fundamental problematizar a efetuação do discurso científico, que provém de uma tradição ocidental (eurocêntrica) de produção de conhecimento, refletindo sobre os validadores epistêmicos e discursivos, os obstáculos epistemológicos e a corporatura da produção científica. Observamos que o próprio pesquisador está envolto em uma rede composta por agentes que manifestam seus interesses econômicos, políticos, culturais e sociais, o que favorece a dependência epistêmica (Adinolfi, 2007).

Ao trazermos a discussão concernente à subjetividade assumimos que o colonialismo - que opera em diversos níveis, dentre os quais, o psíquico -, estrutura a sociedade e mantém as relações de poder por meio de práticas regulatórias e de gerenciamento dos indivíduos. Ademais, a ocidentalização do pensamento exclui, diligentemente, os saberes tradicionais dos povos originários, importando uma visão de mundo eurocêntrica materializada no que pode e no que deve ser dito em ciência e quem pode e deve fazê-lo (Adinolfi, 2007; Quijano, 2005).

Enfatizamos, portanto, a necessidade de nos debruçarmos, enquanto pesquisadores da Ciência da Informação, sobre perspectivas alternativas à análise de fenômenos contemporâneos, especialmente no que tange à compreensão das influências profundas às quais nossas sociedades e, particularmente, nossas mentalidades são submetidas, o que influencia, categoricamente, na produção de conhecimento e na manutenção do discurso de ciência universal.

O presente trabalho tem, por objetivo, traçar um panorama histórico de surgimento do póscolonialismo e da decolonialidade à luz da convergência entre a produção intelectual e os elementos sócio-históricos que a conformam, ao considerar a ausência de pesquisas sobre 
pós-colonialismo e decolonialidade na Ciência da Informação. A discussão é conduzida através do pensamento crítico latino-americano, escolha que se mostra coerente na análise de disputas que dão origem à cartografia epistemológica e às linhas abissais.

\section{SUBVERSÕES CARTOGRÁFICAS: O PRINCÍPIO DE UMA TRAVESSIA}

Iniciamos a discussão compreendendo o Sul Global como categoria para se pensar o projeto político imperialista no século XXI e a sua relação com a emergência dos estudos póscoloniais e decoloniais. São destacados por Ballestrin (2020a) três usos para essa categoria: o descritivo, o identitário e o acadêmico, os quais sintetizamos nos próximos parágrafos.

O uso descritivo se refere à compreensão no léxico das relações internacionais e baseia os programas de cooperação Sul-Sul (Ballestrin, 2020a, 2020c). A noção de Sul emerge no final dos anos 1970 com a apresentação do relatório "Norte-Sul: um Programa para a Sobrevivência", da Comissão Independente de Assuntos Internacionais, que foi constituída em 1977 e presidida por Willy Brandt (Ballestrin, 2020b). A distinção entre Norte e Sul Global é atribuída ao volume de Produto Interno Bruto (PIB) nacional de países no final dos anos 1970, constituindo o parâmetro principal e universal. Essa característica ganha importância na medida em que confere um aspecto positivo à visão de desenvolvimento apresentada no relatório.

Entretanto, não é a primeira vez que o Sul aparece como categoria que determina as relações entre os países imbricados nos processos neocoloniais. Em 1943, o artista plástico uruguaio Joaquín Torres-García publica o desenho "America Invertida" na revista Circulo y Cuadrado, de Montevidéu (Figura 1). Essa produção recria o imaginário subalterno através da inversão geopolítica da América, por meio de uma desconstrução cartográfica que representa os espaços mentais e geográficos ao definir, nas palavras de Torres-García, que "o nosso Norte é o Sul" (Ballestrin, 2020b). 
Figura 1. América Invertida, de Joaquín Torres-García. Montevidéu, 1943.

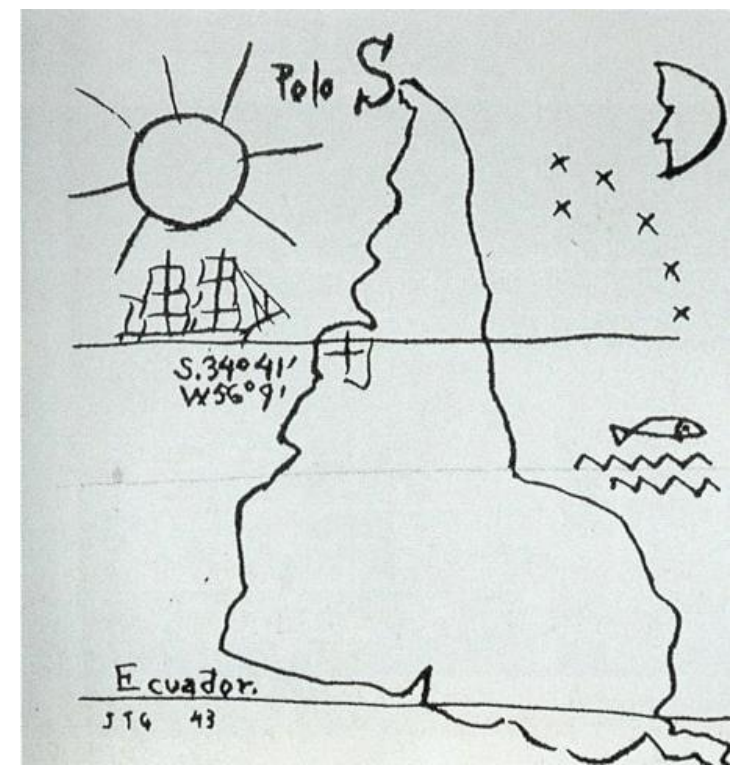

Fonte: Projeto Arte Activo: Catálogo Digital de Artistas Visuales de Uruguay (2014).

Gradualmente se consolida a visão de subalternidade como uma "categoria que projeta uma identidade política [...] reivindicando um diferente caminho e um diferente pertencimento no sistema e na sociedade internacional" (Ballestrin, 2020a). Essa acepção é, igualmente, trazida por Spivak (2010), reconhecendo a figura do subalterno nos meandros dos processos de neocolonialismo e a produção de subjetividade nesse contexto.

É importante destacar que o Sul Global, embora se trate de uma categoria contrahegemônica, tem seu uso, em certa medida, "permitido pela hegemonia pós-colonial multipolar globalizada e neoliberal" (Ballestrin, 2020a). Grovogui (2011) define o Sul como um conjunto de práticas, atitudes e relações sendo, portanto, bastante complexo no que tange aos diversos interesses que o habitam, não limitando-se às fronteiras geopolíticas.

Por sua vez, o uso acadêmico apresenta "desafios metodológicos na intermediação entre uma categoria teórica e as questões empíricas” (Ballestrin, 2020a). É premente a dificuldade de produzir conhecimento e de fazer ciência nas periferias globais. Santos (apud Ballestrin, 2020a) destaca que o Sul fornece "os cenários empíricos, porém, não fornece as próprias conceitualizações, importando-as dos países produtores, em um círculo vicioso". Tal processo nos dá uma ideia de reprodução de agendas políticas, de temáticas de pesquisa e de críticas a teorias, resultando no "epistemicídio de conhecimentos não modernos".

Portanto, o uso acadêmico passa pela produção de conhecimento materializada nas Teorias Sociais do Sul. Ballestrin (2020a) destaca que o Sul agrupa "essas diferentes críticas e denúncias" e se trata de "uma discussão antiga, de colonialismo e imperialismo acadêmico". Ao nos valermos dessa linha de intelecção, destacamos que o processo analítico desta 
pesquisa deve estar coadunado a tal perspectiva. Sublinhamos que a busca por essa coerência está materializada na proposição metodológica anunciada a seguir.

\section{INSURGÊNCIA METODOLÓGICA}

Trata-se de um estudo de natureza aplicada (Fleury, Werlang, 2017) que mapeia o desenvolvimento das perspectivas pós-coloniais e decoloniais de produção intelectual contraposta ao pensamento hegemônico. Em relação aos objetivos, caracteriza-se como um estudo exploratório-investigativo, de abordagem qualitativa, pautada em pesquisa bibliográfica sobre pós-colonialismo e decolonialidade, confrontando tais elementos com manifestações relativas aos distintos agentes científicos, visando explicitar as linhas de composição de uma cartografia epistemológica.

A pesquisa bibliográfica, realizada entre setembro de 2019 e fevereiro de 2020, arrolou o referencial teórico acerca da temática, materializado, fundamentalmente, em livros e artigos científicos (Gil, 2008) que permitiram a composição do texto apresentado na seção subsequente. Para fazê-lo, foram consultados o catálogo do Sistema de Automação de Bibliotecas da Universidade Federal do Rio Grande do Sul (SABi); o Repositório Digital da Universidade Federal do Rio Grande do Sul (LUME); a Base de Dados de Periódicos em Ciência da Informação (BRAPCI); a base de dados Scientific Electronic Library Online (SciELO); e a Red de Bibliotecas Virtuales de Ciencias Sociales de América Latina y el Caribe del Consejo Latinoamericano de Ciencias Sociales (CLACSO).

As interpretações dos resultados seguem as pistas da concreticidade histórica, por meio de percepções dos modos de desenvolvimento da cartografia epistemológica, utilizando-se da dialética para, a partir da produção científica recuperada e analisada, identificar os marcos teóricos, os eventos, os movimentos, as contradições, as rupturas, as influências e as continuidades dos territórios epistêmicos pós-coloniais e decoloniais. Buscamos, nesses elementos de contribuição, a interpretação de acepções subjacentes como forma de elucidar distinções entre estudos pós-coloniais e decoloniais.

\section{O TRAÇAR DAS LINHAS: CONVERGÊNCIAS E DISTINÇÕES ENTRE ESTUDOS PÓS-COLONIAIS E DECOLONIAIS}

Apresentamos os aspectos relativos às interpretações advindas da metodologia proposta, fundamentadas na pesquisa bibliográfica em fontes supramencionadas. $O$ texto a seguir foi composto como resultado desse processo analítico centrado nos documentos recuperados e na apresentação de informações mais representativas para a composição do percurso histórico-político de edificação dos estudos.

O pós-colonialismo deve ser entendido em duas interpretações principais, segundo Santos (2006, p. 581): a primeira se refere ao período histórico que sucede a independência das colônias europeias; já a segunda é "um conjunto de práticas e discursos que desconstroem a 
narrativa colonial escrita pelo colonizador e procuram substituí-la por narrativas escritas do ponto de vista do colonizado". Esta, que nos interessa particularmente no desenvolvimento da pesquisa, se insere

[...] nos estudos culturais, lingüísticos e literários e usa privilegiadamente a exegese textual e as práticas performativas para analisar os sistemas de representação e os processos identitários. Nessa acepção o póscolonialismo contém uma crítica, implícita ou explícita, aos silêncios das análises pós-coloniais na primeira acepção (Santos, 2006, p. 581).

Ballestrin (2017a) atribui três fases para o pós-colonialismo definido na segunda acepção de Boaventura. A primeira é precursora da perspectiva anticolonial, na década de 1950 e 1960, em que duas obras se destacam nesse contexto: Discurso Sobre o Colonialismo (1950) e Pele Negra, Máscaras Brancas (1952).

Na publicação de Discurso Sobre o Colonialismo, Aimé Césaire (1913-2008) abordou o conceito de negritude, debatendo o modo como a população martinicana percebia as suas características étnico-raciais e a complexidade da racialização da sociedade. Césaire (1971) analisou discursos eurocêntricos e sua influência no desenvolvimento da Martinica, sobretudo as manifestações de intelectuais, colonizadores, políticos e missionários de "causas humanitárias".

Por sua vez, na obra Pele Negra, Máscaras Brancas, Frantz Fanon (1925-1961) elaborou sua crítica ao colonialismo a partir dos efeitos do racismo e da desumanização dos agentes envolvidos no processo de colonização, fossem colonizadores ou colonizados. Fanon (2008, p. 28) explora os efeitos dessas formas de violência psicológica compreendendo o duplo processo de manutenção das desigualdades socioeconômicas e a epidermização da inferioridade. Deste modo, temos uma divisão de tipologia da violência: a ação do colonizador, aniquilando o corpo, a psiquê e a cultura do negro no processo de invasão territorial; e a reação violenta dos colonizados na tentativa de se libertar, em um processo autoconsciente de retorno à origem por meio da luta anticolonial (Nayar, 2013).

Tais obras são de fundamental importância para a compreensão do colonialismo e do neocolonialismo no estabelecimento de relações de poder e na produção de subjetividades de tal forma que

Os escritos pós-coloniais precursores possuíram uma forte ligação com o anticolonialismo revolucionário, com as lutas de libertação nacional e com os movimentos de independência, sobretudo na África e na Ásia. Aquilo que podemos chamar de um "pós-colonialismo anticolonial" reuniu intelectuais, ativistas e lideranças, deixando uma produção dispersa, não necessariamente acadêmica, institucionalizada e disciplinada. Na condição pós-colonial, em um sentido temporal estrito, o neocolonialismo começava a ser debatido, sobretudo, como entrave da verdadeira descolonização. [...] Com influências da psicanálise, do pan-africanismo, do pensamento afrodiaspórico e do marxismo revolucionário, a questão da identidade já ali aparecia como fundamental na problematização do colonizado versus 
colonizador e do racismo a serviço do colonialismo (Ballestrin, 2017a, p. 509, itálico da autora).

A segunda fase do pós-colonialismo foi inaugurada em 1978 com a obra Orientalismo, de Edward Said (1935-2003), que discute o uso do conceito homônimo como criação do ocidente para representar de modo exotificado o Oriente (Ásia, Norte da África e Oriente Médio). Para o autor, essa categorização permitiu a permanência de relações de poder, subjugando os povos assim chamados orientais e reforçando a ideia do Ocidente como detentor de modos superiores de cultura e de sociedade (Said, 1990).

Já a obra Pode o Subalterno Falar? (1985), da pesquisadora indiana Gayatri Chakravorty Spivak (1942-), destacou-se no contexto de efetuação dos estudos subalternos pós-coloniais ao questionar a violência epistêmica decorrente da condição etnocêntrica de produção intelectual. O Outro, categoria criada pelo colonialismo (Fanon, 2008), é trazido na centralidade da discussão como uma "voz-consciência" calada pelas formas de violência orquestradas pelo colonialismo/imperialismo. A agência de sua fala e a articulação entre poder, desejo e interesse são, portanto, condicionados por essas conflitantes relações (Spivak, 2010).

O pós-colonialismo de segunda fase, no qual se destacam as obras acima, é compreendido como uma versão "mais hegemônica, canônica, pós estrutural e que populariza o termo póscolonial” (Ballestrin, 2020a). Especialmente Spivak (2010), tal como citado anteriormente, utiliza essa identidade mais "coesa” como estratégia analítico-política.

Nessa fase, as questões de identidade são mais presentes e a diferença é trabalhada "considerando a intensificação das fraturas subalternizadas de raça, gênero e classe ou a valorização da diáspora e do hibridismo criativos resultados do encontro colonial" (Ballestrin, 2017a, p. 509-510). A autora destaca, ainda, a influência dos "estudos pós-estruturalistas, pósmodernos, desconstrutivistas, culturais e subalternos indianos", além da "conjuntura de globalização ascendente e da evidência do multiculturalismo dos anos 1980".

As discussões de gênero têm fundamental importância nesse período. Spivak (2010, p. 6667) defende que se "no contexto da produção colonial, o sujeito subalterno não tem história e não pode falar, o sujeito subalterno feminino está ainda mais profundamente na obscuridade". Entretanto, a articulação do pós-colonialismo desse período com as teorias feministas está mais vinculada aos estudos literários e ao letramento da mulher (Bahri, 2013; Ballestrin, 2017b).

A dialética é marca dos estudos pós-coloniais, como observado em Ballestrin (2017a, 2020b, 2020c), Dussel (2005, 2008), Said (1990), Spivak (1983, 2010) e Quijano (2005). É possível observar que o desenvolvimento dos estudos pós-coloniais foi e ainda é marcado por contrastes bastante importantes, como ocorre na emergência dos estudos decoloniais. 
A terceira fase, chamada de decolonial, é uma inflexão que reivindica a participação da América Latina e a consideração das particularidades de seu processo de desenvolvimento em todas as esferas. Tal perspectiva é norteada pela recuperação das

[...] Contribuições latino-americanas do pós-colonialismo anticolonial, ao mesmo tempo em que pretende se afastar do cânone pós-colonial, inserindo a América Latina no debate e radicalizando a crítica à modernidade e ao eurocentrismo. Aversão pós-colonial latino-americana que certamente recusaria este rótulo para si - constrói seus argumentos com as bases do pensamento latino-americano, filosofia da libertação, teoria da dependência, teoria do sistema-mundo, grupos indiano e latinoamericano de estudos subalternos, filosofia afro-caribenha e feminismo latino-americano [...] (Ballestrin, 2017a, p. 510).

Segundo Grosfoguel (2007), houve um seminário no final dos anos 1990 que reuniu os dois grupos de estudos subalternos vigentes, chamados South Asian Subaltern Studies Group, com a perspectiva asiática, e o Latin American Subaltern Studies Group, que reivindicava a presença latino-americana. Neste momento, alguns participantes do segundo grupo perceberam a necessidade de introduzir elementos específicos dessa outra realidade na elaboração das teorias, tendo em vista a divergência que se assentava: a base teórica sofria forte influência dos assim chamados "quatro guerreiros do apocalipse": Michel Foucault, Jacques Derrida, Antonio Gramsci e Ranajit Guha. Para Grosfoguel (2007) foi constatado que, embora os estudos subalternos pós-coloniais introduzissem a perspectiva latino-americana, permanecia a dependência epistêmica, reforçando a necessidade de descolonizar, inclusive, o póscolonialismo.

Dadas as divergências supracitadas, o grupo latino-americano sofreu uma cisão ocasionada por conflitos de interesses. De um lado, tínhamos o grupo asiático, que concebia a subalternidade como crítica pós-colonial. De outro, o grupo latino-americano, que a compreendia como crítica pós-moderna. E, por fim, dentro do grupo latino-americano, existiam insatisfações quanto à base teórica materializadas na constatação da dependência epistêmica: o segundo grupo falava "sobre os subalternos" e não "com e a partir dos subalternos" (Grosfoguel, 2007). A percepção de Grosfoguel sobre esse evento guarda relação com o estudo de Castro-Gómez (2005), que evidencia o grande desafio latinoamericano: promover a "descolonização das Ciências Sociais e da Filosofia".

É neste contexto que surgiu o Grupo Modernidade/Colonialidade, fruto da divergência teórica com o grupo de estudos subalternos latino-americanos, reunindo pesquisadores dissidentes e incluindo novos integrantes. Alguns participantes já haviam desenvolvido, desde os anos 1970, as próprias linhas de pensamento, dentre as quais se destacam a Filosofia da Libertação, do filósofo argentino Enrique Dussel; a Teoria da Dependência, do sociólogo peruano Aníbal Quijano; e a Teoria do Sistema-Mundo, do sociólogo estadunidense Immanuel Wallerstein.

A estruturação do grupo teve início em 1998 com uma série de eventos científicos que abordaram questões marginais às discussões pós-coloniais vigentes (Grosfoguel, 2007), visto que as questões de raça, gênero e classe se tornaram categorias centrais. A decolonialidade 
surgiu, nesse contexto, como elemento de resistência às cinco ideologias da modernidade: cristianismo, liberalismo, marxismo, conservadorismo e colonialismo. Deste modo, a temática se ampliou de forma significativa na medida em que propôs o afastamento da racionalidade moderna (Ballestrin, 2013).

A colonialidade do saber, conceito proposto por Quijano (2005), foi tema recorrente nas discussões do grupo. Segundo Ballestrin (2013), o conceito esteve constantemente associado à "diferença colonial e geopolítica do conhecimento", trazida por Mignolo. A autora refere que a noção de violência epistêmica, proposta por Foucault, é vista, neste contexto, como insuficiente "para captar o silêncio oriundo do racismo epistêmico, [...] ou a negação da alteridade epistêmica". Assim, o que Foucault não captura é que o eurocentrismo e o colonialismo são "duas faces da mesma moeda".

Discorrendo sobre esses contrastes, Ballestrin (2013) enfatiza que a "diferença colonial epistêmica é cúmplice do universalismo, sexismo e racismo", elaborando a importância de se compreender as opressões em sua densidade histórica e em seu potencial de porosidade e de inter-relação. Essa compreensão, contudo, guarda consonância com as perspectivas adotadas anteriormente pelas fases pós-coloniais, ainda que disponham de nova ótica (latino-americana):

\begin{abstract}
Basicamente, a descolonização é um diagnóstico e um prognóstico afastado e não reivindicado pelo mainstream do pós-colonialismo, envolvendo diversas dimensões relacionadas com a colonialidade do ser, saber e poder. Ainda que assuma a influência do pós-colonialismo, o Grupo Modernidade/Colonialidade recusa o pertencimento e a filiação a essa corrente. $O$ mesmo se aplica às outras influências recebidas que possibilitaram o surgimento e o desenvolvimento da construção teórica do grupo. Contudo, aquilo que é original dos estudos decoloniais parece estar mais relacionado com as novas lentes colocadas sobre velhos problemas latino-americanos do que com o elenco desses problemas em si (Ballestrin, 2013, p. 108, itálico da autora).
\end{abstract}

As reivindicações decoloniais, portanto, não operam de forma homogênea. Tampouco poderiam sê-lo: é prioritário reconhecer a complexidade da formação dos territórios latinoamericanos com suas relevantes diferenças culturais, históricas e de interesses. É imperativo pautá-las no reconhecimento dessas diferenças, permitindo a dinamização dos discursos de modo a acolher diferentes epistemologias no exercício da criticidade. Contudo, nos últimos anos, é perceptível o tensionamento entre os pesquisadores que se debruçam sobre o colonialismo e os pesquisadores de orientação marxista que consideram o imperialismo na centralidade da discussão. Há, em curso, uma espécie de “divisão de tarefas” que ressalta a importância de abordar o imperialismo e o colonialismo como categorias indissociáveis (Ballestrin, 2017a). O reconhecimento de tais diferenças implica em desvelar tensionamentos oriundos de discursos científicos hegemônicos, consideradas as complementaridades e discrepâncias dessas perspectivas epistemológicas. 


\section{O TERRITÓRIO EPISTÊMICO: TENSIONAMENTOS EM FRONTEIRAS DO DISCURSO CIENTÍFICO}

A noção de hegemonia, refletida por Gramsci (1978), reitera a necessidade de se inteirar sobre a origem de nossa compreensão de mundo, que é pontualmente vinculada a algum tipo de conformismo, na medida em que são assimilados os discursos que dão sentido à sociedade. A consciência crítica somente é possível a partir do entendimento das disputas de hegemonias contrastantes, resultando em uma elaboração superior do real, ou seja, a superação de uma noção meramente herdada e absorvida. A constituição da historicidade individual é fundamental na participação ativa da produção de história do mundo.

Portelli (1977) aponta que a criação de um bloco ideológico comum às relações intersocietárias permite à classe dominante manter o monopólio intelectual. Este seria, portanto, o fator fundamental para a manutenção da hegemonia. Para que as classes subalternas possam criar um novo bloco histórico devem romper com o sistema hegemônico da classe dominante, formando sua própria camada de "intelectuais orgânicos", que possam pensar o mundo a partir de sua realidade.

A colonialidade do saber, como abordado anteriormente, influencia o desenvolvimento das Ciências Sociais, atravessando-as pelas relações de poder que se reorganizam no contexto imperialista. A episteme se sustenta nessa estrutura que legitima apenas as manifestações alinhadas à hegemonia dominante, invisibilizando os discursos contrapostos à lógica de produção de conhecimento. Simbioticamente, o conhecimento hegemônico é estruturado, desenvolvido e difundido a partir da noção moderna de "ciência universal", que invade a periferia (Sul) e se estabelece como normativa (Tirado, 2009).

A violência epistêmica decorrente desse processo é um modo de exercício do poder simbólico do Norte em relação ao Sul. As narrativas da realidade, segundo Spivak (2010), foram estabelecidas como normativas impedindo que outros modos de interpretar o mundo tivessem importância. Mais do que isso: é notória a tentativa de exterminá-los, ocasionando, assim, práticas de epistemicídio. A autora define que o mais claro exemplo disponível de tal violência epistêmica é o projeto remotamente orquestrado, vasto e heterogêneo de se constituir o sujeito colonial como Outro. Esse projeto é também a obliteração assimétrica do rastro desse outro em sua precária Subjetividade (Spivak, 2010, p. 47).

Gnecco (2009) reflete que essa imposição de modos de ver, de interpretar o mundo e de produzir conhecimento impossibilita a inclusão de epistemologias alternativas, resultando na alteração da cosmovisão dos povos colonizados e na conformação, cada vez mais constante, de narrativas válidas na produção de conhecimento.

As diferenças abissais entre Norte e Sul são intensificadas pela dependência epistêmica, que se reflete na ausência de autonomia para produzir as próprias bases teóricas e na validação do discurso científico. Entretanto, não devemos interpretar essas relações como um bloco 
único. É fundamental compreendê-las em sua heterogeneidade e particularidades dos países componentes do Sul:

\begin{abstract}
Assim como na economia e na sociedade, a dicotomia centro-periferia também está presente na ciência. Em ambos os casos, a periferia [Sul] tende a ser dependente do centro [Norte]. O sistema de valores centrais constitui assim a zona central da ciência. Os valores centrais são seguidos em maior ou menor grau pelas zonas periféricas, que enxergam no centro um modelo a ser seguido, com valores e crenças a serem incorporados. [...] Por outro lado, quanto mais dispersos estiverem os espaços periféricos, menores parecem ser as oportunidades da inversão da ordem central da ciência mainstream. O próprio centro não é coeso e a complexidade dos dias atuais contribui para o estabelecimento de centros menores no espaço fragmentado da ciência principal (Santin, 2019, p. 29).
\end{abstract}

Lander (2005) defende que boa parte dos entraves no avanço das alternativas teóricas e políticas está na percepção distorcida do neoliberalismo. Para o autor, debatê-lo e combatêlo unicamente como uma teoria econômica é infrutífero, visto que se trata de um discurso hegemônico e de um modelo civilizatório. De fato, sua crítica concebe que as relações sociais e os modos de operação e de reconfiguração do poder e da dominação não se desvinculam da produção de conhecimento. É justamente o processo de estabelecimento dessas relações que propicia a formação de uma cartografia epistemológica que conforma o discurso científico:

Essa força hegemônica do pensamento neoliberal, sua capacidade de apresentar sua própria narrativa histórica como conhecimento objetivo, científico e universal e sua visão da sociedade moderna como a forma mais avançada - e, no entanto, a mais normal - da experiência humana, está apoiada em condições histórico-culturais específicas. O neoliberalismo é um excepcional extrato purificado e, portanto, despojado de tensões e contradições, de tendências e opções civilizatórias que têm uma longa história na sociedade ocidental. Isso lhe dá a capacidade de constituir-se no senso comum da sociedade moderna. A eficácia hegemônica atual desta síntese sustenta-se nas tectônicas transformações nas relações de poder ocorridas no mundo nas últimas décadas. $O$ desaparecimento ou derrota das principais oposições políticas que historicamente se confrontavam com a sociedade liberal (o socialismo real e as organizações e lutas populares anticapitalistas em todas as partes do mundo), bem como a riqueza e o poderio militar sem rivais das sociedades industriais do Norte, contribuem para a imagem da sociedade liberal de mercado como a única opção possível, como o fim da História. No entanto, a naturalização da sociedade liberal como a forma mais avançada e normal de existência humana não é uma construção recente que possa ser atribuída ao pensamento neoliberal, nem à atual conjuntura política; pelo contrário, trata-se de uma ideia com uma longa história no pensamento social ocidental dos últimos séculos (Lander, 2005, p. 8).

Para Scribano (2020), a lógica de expansão do capital em nível global é multipolar, multicêntrica e, sendo reticular, atinge-nos desde os poros. É fundamental, portanto, reconhecer a sua capacidade de se espalhar e de nos contaminar de modos muito refinados 
e sutis. Neste ponto, cabe pensarmos como essa lógica opera na produção de subjetividade vinculada à produção científica.

O processo de constituição do cientista e do discurso científico é pontuado por Adinolfi (2007) como uma imbricada relação de formação discursiva e de assujeitamento. O pesquisador passa por um treinamento através do qual aprende as importâncias, os modos de expressão e as narrativas consideradas válidas pela academia. Os sentidos são determinados a partir do que se entende por verdade. Entretanto, é crucial lembrar que as "narrativas de verdade", como vimos anteriormente, são oriundas do estabelecimento de relações de poder e de dominação:

\begin{abstract}
Essa metalinguagem científica constitui-se de códigos de circulação restrita à comunidade científica, dominados apenas por seus membros, através de extenso treinamento - em si, um processo de assujeitamento a uma formação discursiva específica, própria para o exercício da ciência, através de mecanismos de controle dos sentidos permitidos e não permitidos, de verdade e não-verdade. Os códigos que constituem essa metalinguagem se apresentam ilusoriamente neutros, objetivos, lineares e a-históricos (Adinolfi, 2007, p. 2-3).
\end{abstract}

A complexidade desse processo é tangível pelo texto da autora que traz a perspectiva foucaultiana. Existe uma "ilusão de saberes cristalizados, a-históricos, universais, neutros e o objetivos [pelos quais] a ciência se constitui, estabelecendo uma linguagem que pretensamente traz as mesmas características" (Adinolfi, 2007, p. 7). É ingênuo pensar que não há forças que operam silenciosamente (ou invisivelmente, nas linhas abissais) no estabelecimento dessas verdades universais. Pretendê-las "neutras" é estar em sintonia com o imperialismo acadêmico.

Tal discurso de neutralidade é parte do processo compreendido por Rampinelli e Ouriques (2017) como a alienação do conhecimento na elaboração de sua crítica à razão acadêmica. Para os autores, o imperialismo acadêmico se utiliza de validadores científicos, entre outros mecanismos, para alienar a produção intelectual. Esta seria, portanto, uma validação burocrática do conhecimento.

O conhecimento e a produção intelectual são vistos como mercadorias no sistema capitalista, em que os critérios quantitativos se sobressaem, o que se relaciona com a divisão internacional do trabalho. Novamente, o capitalismo e o imperialismo operam em uma lógica imanente de conformação da realidade estabelecida pelo eurocentrismo e pelas acepções do pensamento moderno.

Rampinelli e Ouriques (2017) destacam, ainda, que, para auferir a produção científica no sistema capitalista se considera, majoritariamente, a produção tecnológica e o registro de patentes. No caso estadunidense temos um complexo processo de articulação entre as empresas multinacionais que determinam os interesses e fornecem infraestrutura; e o financiamento estatal, o orçamento militar e os fundos universitários para a concessão de bolsas de pesquisa na execução de projetos que, por sua vez, resultam no desenvolvimento 
tecnológico, no registro de patentes e na confecção de produtos em escala global para atender as demandas das multinacionais. Estes produtos, por fim, são exportados e comercializados nos países do Sul.

O conflito entre Norte e Sul é complexo e heterogêneo. Destaca-se que "o pico do centro já não é tão alto, talvez não seja o único, e a periferia não está mais tão distante, embora isso não a torne menos periférica" (Santin, 2019, p. 30). Entretanto, as desigualdades se mostram cada vez mais presentes. Deste modo, as tensões entre Norte e Sul podem gerar situações de dependência ou de revolta. A autora reflete que, através dessa perspectiva, "os indicadores bibliométricos podem tanto contribuir para a manutenção das posições centrais ou periféricas como apresentar-se como alternativas para novos olhares sobre a ciência das periferias" (Santin, 2019, p. 31).

A publicação em revistas científicas é outro ponto que merece ênfase. A indexação dos periódicos em bases internacionais é parte do mecanismo de manutenção das estruturas de poder que conformam a ciência mundial. A presença de grandes editores que controlam a publicação científica é fator fundamental na análise, visto que as dinâmicas de controle na produção científica privilegiam temáticas e metodologias que geram impacto nos países centrais em detrimento dos países periféricos (Santin, 2019; Silveira, Benedet, SantillánAldana, 2018).

Todavia, cabe evidenciar que esse sistema não teria raízes e não se sustentaria no Sul se não fosse reproduzido pelos próprios agentes de nossos países. Gudynas (2017), em artigo para Ecuador Debate, reforça a importância das revistas latino-americanas no enfrentamento à subordinação epistêmica em um processo de "retomada de nossas próprias vozes", em que pese a qualificação das revistas para que estejam mais equânimes no campo da disputa epistemológica, política e social. No entanto, o autor destaca que, "para além das dificuldades conjunturais, existe um processo mais profundo que parte de uma política do saber, da qual somente se permite 'falar' em um contexto globalizado seguindo um determinado formato" (Gudynas, 2017, p. 17, tradução nossa).

O Fator de Impacto resultante da média de citações dos artigos publicados é mais um indicativo de manutenção do status quo. As críticas ao indicador se referem ao viés de cobertura das revistas publicadas em inglês, ao favorecimento de representação das Ciências Exatas e a minoração da presença de revistas das áreas de Ciências Humanas, Ciências Sociais ou provenientes de regiões periféricas (Santin, 2019).

Como vimos, existe uma rede de práticas que envolvem o pesquisador e o impedem, inclusive, de compreender esse processo de alienação no sistema de divisão internacional do trabalho, aspecto que reproduz a dinâmica do sistema capitalista. Os intelectuais que se sobressaem em suas áreas de pesquisa são arregimentados dos países do Sul, recebendo grandes oportunidades nos países do Norte, para que produzam avanços tecnológicos e científicos materializados em produtos que serão, mais tarde, comercializados e consumidos pelos países do Sul. 
Ao mesmo tempo, os professores estão cativos desse sistema, cuja simbiose se articula, entre outros meios, pela cultura de avaliação por pares e no incentivo à publicação em periódicos internacionais que possuem maior prestígio e que garantem uma melhor pontuação. A universidade, mais uma vez, opera ensimesmada em uma lógica alienante e de parcialização do trabalho. O pesquisador, envolto nessa teia, não se percebe como parte do engendramento que o eleva às categorias de produtor e produto desse sistema.

Rampinelli e Ouriques (2017) reforçam que há uma dinâmica ocorrendo no campo político do liberalismo e do conservadorismo: a ciência não tem validação social. O distanciamento entre o fazer científico e a população é tão abismal que não há espaço para se constituírem os "intelectuais orgânicos", os pensadores das questões próprias e específicas do país. A elitização do acesso à universidade permite que sejam mantidas e intensificadas profundas diferenças entre quem está dentro da universidade e quem está fora dela. É consequência desse processo a perseguição recente às Ciências Humanas, vistas como ameaça à lógica neoliberal. Para os autores, a universidade é um terreno de conformação, de modo que a autonomia intelectual sucumbe.

Em 1969, no livro A Universidade Necessária, Darcy Ribeiro já destacava o sentido de urgência em romper com a lógica que impera na academia, reforçando que o papel da universidade deve ser de discutir problemas, produzir conhecimento e contribuir com o desenvolvimento de seu país. No entanto, como vimos, a conformação apenas se acentuou no percurso histórico de estabelecimento do imperialismo acadêmico e na remanescência das colonialidades geradas pela dominação colonial.

\section{CONSIDERAÇÕES FINAIS}

No percurso de execução deste estudo buscamos compreender e explicitar a permanência do colonialismo no discurso científico que, através da produção científica, conforma a cartografia epistemológica. Os estudos pós-coloniais e decoloniais, ainda que se apresentem como tensionamentos epistemológicos, guardam profundas relações com os interesses imperialistas. A dependência epistêmica, resultado desse processo, têm sua vigência nas relações de poder que não se encerram em binarismos como "colonizadores e colonizados", “dominantes e dominados", "Norte e Sul Global” ou "centro e periferia".

Outrossim, os mecanismos de dominação e de manutenção do poder se aprimoram na medida em que se difunde a ideia de emancipação intelectual do Sul. Defendemos que as opressões decorrentes do processo colonizatório devem ser compreendidas em sua densidade histórica e dimensionadas na possibilidade de se sutilizarem, assumindo uma forma reticular. Especialmente as questões de raça, gênero e classe são intersecções fundamentais no estabelecimento de tais análises.

A dependência epistêmica deve ser observada em sua articulação à dependência socioeconômica, visto que são duas faces de uma mesma moeda: o colonialismo que se ramifica nas colonialidades do saber, do ser e do poder; e o eurocentrismo. Deste modo, não 
é possível discutir a iminência de novas epistemologias e a criação de Teorias Sociais do Sul sem considerar as influências políticas dos países imperialistas, do Norte Global, inclusive na produção científica.

A subversão da lógica de dependência epistêmica ameaça a hegemonia em todas as suas faces. Por esta razão, é fundamental compreender que o discurso de ciência universal tem, como principal importância, manter o funcionamento das engrenagens que estruturam as cartografias abissal e epistemológica. Encerramos essa discussão ressaltando, novamente, a importância de historicizar os discursos e de compreender sua implicação teórica, social e epistemológica no estabelecimento de narrativas válidas, aceitáveis e produtoras de verdades. Defendemos, mais uma vez, que esse intento só se completa quando conhecemos e reconhecemos a nossa historicidade.

Deste modo, ao tomarmos consciência de nosso papel nos engendramentos das articulações entre Sul e Norte - propositalmente invertidos nesse final de trabalho - , seja nas relações Sul-Sul, Sul-Norte ou mesmo questões internas de cada país, é possível construir uma outra realidade, que nos tire do lugar de cativos e nos eleve à condição de produtores da própria História, visando à soberania de nossas nações e à descolonização psíquica e material. É urgente que essa consciência se materialize na Ciência da Informação, área fortemente ligada ao eurocentrismo que tem, na concreticidade dos instrumentos de avaliação da ciência, as ferramentas para desvelar as diferenças abissais que conformam o discurso científico ou participar na manutenção de suas linhas.

\section{REFERÊNCIAS}

ADINOLFI, Valéria Trigueiro Santos. Discurso científico, poder e verdade [em linha]. Revista Aulas, São Paulo, v. 1, n. 3, p. 1-10, dez./mar. 2007. [Acesso em 22 agosto 2020]. Disponível em: https://www.ifch.unicamp.br/ojs/index.php/aulas/article/view/1940.

BAHRI, Deepika. Feminismo e/no pós-colonialismo [em linha]. Revista Estudos Feministas, Florianópolis, v. 21, n. 2, p. 659-688, maio/ago. 2013. [Acesso em 17 setembro 2020].

Disponível em: http://www.scielo.br/scielo.php?script=sci arttext\&pid=S0104$\underline{026 \times 2013000200018 \& \operatorname{lng}=e n \& n r m=i s o}$

BALLESTRIN, Luciana. Aula 1: o Sul Global como projeto político [em linha]. Disciplina de Teoria Social e os Desafios Pós-coloniais. 1 vídeo (1h 59min 49s). Periféricas: Núcleo de Estudos em Teorias Sociais, Modernidades e Colonialidades, UFBA, Salvador, $2020 a$. [Acesso em 08 setembro 2020]. Disponível em: https://www.youtube.com/watch?v=5nLOU4Zofig

BALLESTRIN, Luciana. Modernidade/Colonialidade sem "Imperialidade"? O Elo Perdido do Giro Decolonial [em linha]. Dados, Rio de Janeiro, v. 60, n.2, p. 505-540, abr./jun. $2017 a$. [Acesso em 12 setembro 2020]. Disponível em: 
https://www.scielo.br/scielo.php?script=sci_arttext\&pid=S0011$52582017000200505 \&$ lng=pt\&tlng=pt

BALLESTRIN, Luciana. O Sul Global como projeto político [em linha]. Horizontes ao Sul, 15 jul. 2020. 2020b. [Acesso em 12 setembro 2020]. Disponível em:

https://www.horizontesaosul.com/single-post/2020/06/30/O-SUL-GLOBAL-COMO-PROJETOPOLITICO.

BALLESTRIN, Luciana. América Latina e o giro decolonial [em linha]. Revista Brasileira de Ciência Política, Brasília, v. 11, p. 89-117, 2013. [Acesso em 14 setembro 2020]. Disponível em: https://periodicos.unb.br/index.php/rbcp/article/view/2069.

BALLESTRIN, Luciana. Feminismo De(s)colonial como Feminismo Subalterno LatinoAmericano [em linha]. Revista Estudos Feministas, Florianópolis, v. 28, n. 3, p. 1-14, ago. 2020c. [Acesso em 18 outubro 2020]. Disponível em:

https://www.scielo.br/scielo.php?script=sci_arttext\&pid=S0104026X2020000300200\&tlng=pt

BALLESTRIN, Luciana. Feminismos Subalternos [em linha]. Revista Estudos Feministas, Florianópolis, v. 25, n. 3, p. 1035-1054, set./dez. 2017b. [Acesso em 18 outubro 2020]. Disponível em: http://www.scielo.br/scielo.php?script=sci arttext\&pid=S0104$\underline{026 \times 2017000301035 \& \operatorname{lng}=p t \& n r m=i s 0}$

CASTRO-GÓMEZ, Santiago. Ciências Sociais, violência epistêmica e o problema da "invenção do outro" [em linha]. Em: LANDER, Edgardo (Org.). A Colonialidade do Saber: eurocentrismo e Ciências Sociais - Perspectivas latino-americanas. Colección Sur Sur. Buenos Aires:

CLACSO, 2005. [Acesso em 13 setembro 2020]. Disponível em: http://biblioteca.clacso.edu.ar/ar/libros/lander/pt/lander.html.

CÉSAIRE, Aimé. Discurso sobre o Colonialismo. Porto: Poveira, 1971.

DUSSEL, Enrique. Europa, Modernidade e Eurocentrismo [em linha]. Em: LANDER, Edgardo (Org.). A Colonialidade do Saber: eurocentrismo e Ciências Sociais - Perspectivas Latinoamericanas. Colección Sur Sur. Buenos Aires: CLACSO, 2005. [Acesso em 13 setembro 2020]. Disponível em: http://biblioteca.clacso.edu.ar/ar/libros/lander/pt/lander.html.

DUSSEL, Enrique. Meditaciones anti-cartesianas: sobre el origen del anti-discurso filosófico de la Modernidad [em linha]. Tabula Rasa, Bogotá, n. 9, p. 153-197, 2008. [Acesso em 13 setembro 2020]. Disponível em: http://www.scielo.org.co/scielo.php?pid=S1794$\underline{24892008000200010 \& \text { script }=\text { sci } \text { abstract\&tlng=pt }}$

FANON, Frantz. Pele Negra, Máscaras Brancas. EDUFBA: Salvador, 2008.

FLEURY, Maria Tereza Leme; WERLANG, Sergio Ribeiro da Costa. Pesquisa aplicada: conceitos e abordagens [em linha]. Anuário de Pesquisa GVPesquisa, São Paulo, nov. 2017. [Acesso em 13 setembro 2020]. Disponível em: http://bibliotecadigital.fgv.br/ojs/index.php/apgvpesquisa/article/view/72796/69984.

GIL, Antônio Carlos. Métodos e Técnicas de Pesquisa Social. 6 ed. São Paulo: Atlas, 2008. 
GNECCO, Cristóbal. Caminos de la Arqueología: de la violencia epistémica a la relacionalidad [em linha]. Boletim do Museu Paraense Emílio Goeldi - Ciências Humanas, Belém, v. 4, n. 1, p. 15-26, 2009. [Acesso em 13 setembro 2020]. Disponível em: https://www.scielo.br/scielo.php?pid=S1981-81222009000100003\&script=sci abstract

GRAMSCI, Antonio. Concepção Dialética da História. Rio de Janeiro: Civilização Brasileira, 1978.

GROSFOGUEL, Ramón. The Epistemic Decolonial Turn [em linha], Cultural Studies, London, v. 21, n. 2, p. 211-223, 2007. [Acesso em 25 setembro 2020]. Disponível em: https://www.tandfonline.com/doi/full/10.1080/09502380601162514.

GROVOGUI, Siba. A Revolution Nonetheless: The Global South in International Relations [em linha]. The Global South, Bloomington, v. 5, n. 1, p. 175-190, 2011. [Acesso em 25 outubro 2020]. Disponível em: https://muse.jhu.edu/article/449224.

GUDYNAS, Eduardo. Sin nuestras propias revistas académicas latino-americanas seríamos mudos [em linha]. Ecuador Debate, Quito, n. 100, p. 45-60. [Acesso em 23 outubro 2021]. Disponível em: https://repositorio.flacsoandes.edu.ec/xmlui/handle/10469/13566.

LANDER, Edgardo. Ciências Sociais: saberes coloniais e eurocêntricos [em linha]. Em: LANDER, Edgardo. (Org.). A Colonialidade do Saber: eurocentrismo e Ciências Sociais Perspectivas latino-americanas. Colección Sur Sur. Buenos Aires: CLACSO, 2005. [Acesso em 14 setembro 2020]. Disponível em: http://biblioteca.clacso.edu.ar/ar/libros/lander/pt/lander.html.

NAYAR, Pramond K. Frantz Fanon. Abingdon: Routledge, 2013.

PORTELLI, Hugues. Gramsci e o Bloco Histórico. Rio de Janeiro: Paz e Terra, 1977.

RAMPINELLI, Waldir José; OURIQUES, Nildo. Crítica à razão acadêmica: reflexão sobre a universidade contemporânea, v. 1. Florianópolis: Insular, 2017.

RIBEIRO, Darcy. A Universidade Necessária. Rio de Janeiro: Paz e Terra, 1969.

QUIJANO, Aníbal. Colonialidade do Poder, Eurocentrismo e América Latina [em linha]. Em: LANDER, Edgardo (Org.). A Colonialidade do Saber: eurocentrismo e Ciências Sociais Perspectivas latino-americanas. Colección Sur Sur. Buenos Aires: CLACSO, 2005. [Acesso em 25 setembro 2020]. Disponível em:

http://biblioteca.clacso.edu.ar/ar/libros/lander/pt/lander.html

SAID, Edward. Orientalismo: o Oriente como invenção do Ocidente. São Paulo: Companhia das Letras, 1990.

SANTIN, Dirce Maria. Ciência mainstream e periférica da América Latina e Caribe: configurações e padrões de especialização. 2019. Tese (Doutorado em Comunicação e Informação). Faculdade de Biblioteconomia e Comunicação. Universidade Federal do Rio Grande do Sul. Porto Alegre, 2019. $171 \mathrm{f}$.

SANTOS, Boaventura de Sousa. Entre Próspero e Caliban: Colonialismo, Pós-Colonialismo e Interldentidade. Em: SANTOS, Boaventura de Sousa. A gramática do tempo: para uma nova 
cultura política. São Paulo: Cortez, 2006. Capítulo 7, p. 227 - 276. (Coleção para um novo senso comum; v. 4).

SANTOS, Boaventura de Sousa. Para além do Pensamento Abissal: das linhas globais a uma ecologia de saberes [em linha]. Novos Estudos, CEBRAP, São Paulo, n. 79, p. 71-94, nov.

2007. [Acesso em 14 setembro 2020]. Disponível em:

https://www.scielo.br/scielo.php?script=sci arttext\&pid=S0101-

$33002007000300004 \&$ Ing=pt\&nrm=iso

SILVEIRA, Lúcia da; BENEDET, Lara; SANTILLÁN-ALDANA, Julio. Interpretando a internacionalização dos periódicos científicos brasileiros [em linha]. Motrivivência, Florianópolis, v. 30, n. 54, p. 90-110, jul. 2018. [Acesso em 23 setembro 2020]. Disponível em: https://periodicos.ufsc.br/index.php/motrivivencia/article/view/2175-8042.2018v30n54p90/0

SCRIBANO, Adrián. Aula 2: Teorias Sociais do Sul [em linha]. Disciplina de Teoria Social e os Desafios Pós-coloniais. 1 vídeo (1h 39min 34s). Periféricas: Núcleo de Estudos em Teorias Sociais, Modernidades e Colonialidades. UFBA. Salvador, 2020. [Acesso em 15 setembro 2020]. Disponível em: https://www.youtube.com/watch?v=8M4d7j1Blvs.

SPIVAK, Gayatri Chakravorty. Displacement and the Discourse of Woman. Em: KRUPNIK, Mark (Org.). Displacement: Derrida and After. Bloomington: Indiana University Press, 1983.

SPIVAK, Gayatri Chakravorty. Pode o Subalterno Falar? Belo Horizonte: UFMG, 2010.

TIRADO, Genara. Violencia Epistémica y Descolonización del Conocimiento [em linha]. Sociocriticism, Granada, v. 24, n. 1-2, p. 173-201, 2009. [Acesso em 23 setembro 2020]. Disponível em: https://dialnet.unirioja.es/servlet/articulo?codigo=4637301. 